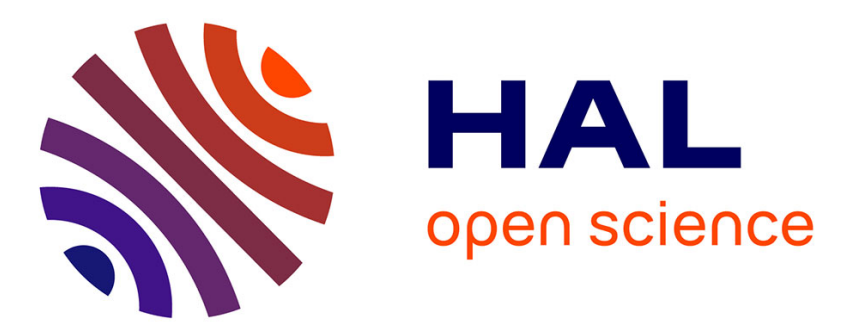

\title{
AN INNOVATIVE MAPPING OF HYDROCLIMATIC TIME SERIES OF THE NIGER WATERSHED BY INVERTING GRACE KBR RANGES ON A BASIS OF SURFACE SLEPIAN FUNCTIONS
}

G L Ramillien, J Darrozes, L Seoane

\section{- To cite this version:}

G L Ramillien, J Darrozes, L Seoane. AN INNOVATIVE MAPPING OF HYDROCLIMATIC TIME SERIES OF THE NIGER WATERSHED BY INVERTING GRACE KBR RANGES ON A BASIS OF SURFACE SLEPIAN FUNCTIONS. IGARSS 2021, Jul 2021, Bruxelles, Belgium. hal-03374638

\author{
HAL Id: hal-03374638 \\ https://hal.science/hal-03374638
}

Submitted on 12 Oct 2021

HAL is a multi-disciplinary open access archive for the deposit and dissemination of scientific research documents, whether they are published or not. The documents may come from teaching and research institutions in France or abroad, or from public or private research centers.
L'archive ouverte pluridisciplinaire HAL, est destinée au dépôt et à la diffusion de documents scientifiques de niveau recherche, publiés ou non, émanant des établissements d'enseignement et de recherche français ou étrangers, des laboratoires publics ou privés. 


\title{
AN INNOVATIVE MAPPING OF HYDROCLIMATIC TIME SERIES OF THE NIGER WATERSHED BY INVERTING GRACE KBR RANGES ON A BASIS OF SURFACE SLEPIAN FUNCTIONS
}

\author{
G. L. Ramillien (1,2), J. Darrozes (1,3), L. Seoane (1,3) \\ (1) Géosciences Environnement Toulouse (GET), Observatoire Midi-Pyrénées (OMP) \\ (2) Centre National de la Recherche Scientifique (CNRS) \\ (3) Université Paul Sabatier Toulouse (UPS), Earth Sciences Department
}

\begin{abstract}
We propose to use a regional orthogonal Slepian Functions (SF) decomposition to represent and analyse the surface water mass variations sensed by GRACE satellite over the Niger basin. As band-limited Spherical Harmonics (SH) remain not adapted for describing hydrological signals in small geographical areas, Slepian functions can solve the signal energy loss by searching the concentration of information in both spatial and spectral domains of various size and shape. Another advantage of using such regionallydefined basis of orthogonal functions is the drastic reduction of the problem dimensions, so that much faster computation of only a few coefficients, instead of thousands of SH. We propose to use SF to adjust the corresponding 10-day SF coefficients for the semi-arid Niger basin from real geopotential data of the GRACE gravimetry mission. Multiyear time series of the Niger coefficients retrieve the seasonal cycle including a short-wet season every end of summer.
\end{abstract}

Index Terms - GRACE, Slepian functions, continental hydrology, Niger.

\section{INTRODUCTION}

Launched in March 2002 by NASA and DLR, the Gravity Recovery and Climate Experiment (GRACE) mission belongs to a new generation of Low-Earth Orbiter (LEO) satellites that improves the resolution of the gravity field to $300-400 \mathrm{~km}[1,2]$. In particular, the GRACE mission has been mapping the tiny changes of the gravity field that correspond to water mass transfers inside fluid envelops of our planet, i.e. atmosphere, oceans, continental water/ice storage.

Different ways for representing and analysing the GRACE signal have been proposed. Spherical Harmonics (SH) have been historically used to recover low degrees (or long wavelengths) of the gravity field from precise satellite trajectories, e.g. by laser telemetry. Unfortunately, SH suffer from spectrum truncation that causes spatial leakage. As they constitute a basis of orthogonal functions on the entire sphere and they are no longer optimal while studying small areas, the orthogonality and energy property are lost. Without orthogonality, any regional decomposition is not unique and ensured.

A representation in Slepian Functions (SF) that maximizes the information density in spatial and spectral domains is adopted in the present study. Extracting information over the full bandwidth of the solution without filtering, the SF basis provides spatial sensitivity that is superior to the sensitivity of many other modelling methods. It consists of building a finite set of orthogonal functions in a given region, as earlier proposed by [3] to solve geodetic localization problems. Former studies on applications of Slepian functions concerned the characterization of deep deformation of important earthquakes by their signature in the gravity field measured by GRACE. It is possible to isolate the coseismic gravity variation due to the 2004 Sumatra-Adaman earthquake [4], while [5] studied the Tohoku earthquake of 2011. In hydrology, the total mass loss of Greenland by melting has been made by [6] using GRACE data between 2002 - 2011. Mass balance of the Tibetan Plateau and its surrounding glaciers that have been losing ice mass due to the global warming, was also quantified by [7]. The effects of coal mining that causes groundwater depletion consumption in the Loess Plateau were explored using SF representation [8]. Re-evaluation of the mass balance of the Iceland ice cap using SF have been also made by [9], where considering a whole continent limited spatial leakage.

So far, the first SF modes have been derived from spherical harmonics basis by imposing a certain bandwidth of $L=60$ for GRACE data. They are commonly derived considering the method of [6] and coded in [10] to transform the GRACE Stokes coefficients, i.e. dimensionless SH coefficients of the geopotential, into a regional SF basis. We propose here to use this set of SF to recover the hydrological variations of the semi-arid basin of the Niger river to restore the SF coefficients directly from the along-track GRACE geopotential data for 10-day periods. 


\section{THE NIGER BASIN CLIMATE}

With a surface of 2.27 millions of $\mathrm{km}^{2}$ shared by ten countries and a population of almost 100 millions of people, the Niger river basin is one of the most important river system of Africa (Figure 1). Its length of 4,200 km makes it the third longest river of the continent after Congo and Nile. Its average annual discharge is $\sim 5500 \mathrm{~m}^{3} / \mathrm{s}$. It supports largescale irrigation, fisheries and livestock herding and agriculture (mainly cotton and rice), provides drinking water, generates hydropower and allows navigation. Its discharge at Koulikoro in Nigeria is about $32.5 \mathrm{~km}^{3}$ per year (average of 1970-1998).

The Niger river crosses areas with different climatic characteristics. It has a clear latitudinal zonation marked in the north by a desert climate (Sahara desert) which changes to a semi-arid band with savannas and ends in the south in the estuarine zone by a tropical band according to the Köppen climate classification. Due to the topography and hydrology, the basin is generally divided into four subregions: the Upper Niger, the Central Delta, the Middle Niger and the Lower Niger.

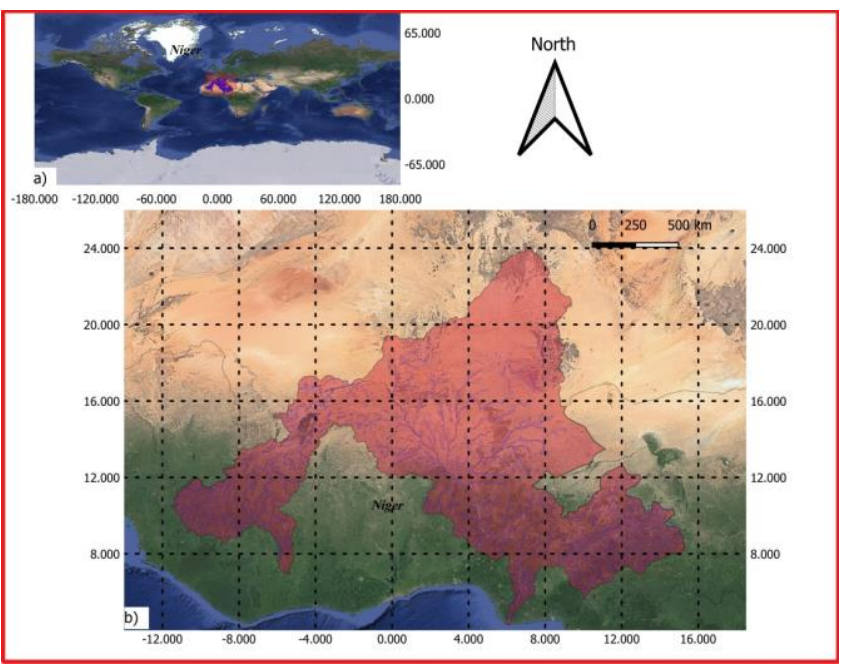

Figure 1. Geographical localization of the Niger river basin. Latitudes and longitudes are in decimal degrees.

The region is characterized by wet $(\sim 4 \mathrm{~mm}$ of average rainfall) and dry ( $\sim 0.4 \mathrm{~mm}$ of average rainfall) seasons, the latter being significantly longer in the Sahel zone. The seasonal pattern and amount of rainfall in all areas depend on the latitude and position of the Inter-Tropical Convergence Zone (ITCZ) which migrates between North and South during the year.

\section{GRACE KBRR DATA}

The on-board K-Band Range Rate (KBRR) system measures the dual one-way change of range of the baseline between the two co-planar GRACE satellites with a precision of $\sim 0.1 \mu \mathrm{m} / \mathrm{s}$ on the velocity difference or equivalently $10 \mu \mathrm{m}$ in terms of Line-Of-Sight (LOS) distance after integration versus time [11,12], while the average distance between the two GRACE vehicles is $~ 220$ $\mathrm{km}$. The Level-1B data are the most precise measurements of the gravity variations sensed by the satellite tandem with an accuracy of $10^{-7} \mathrm{~m} / \mathrm{s}$, which gives access to surface water mass transfers. Coupled with the accurate 3-axis accelerometers measuring the effects of forces acting on the satellites, i.e. atmospheric drag and solar pressure, a priori models for atmosphere and oceanic masses, including polar and sloid tides, are used to compute along-track 5-second KBRR residuals by least-squares dynamical orbit determination.

The daily positions of both GRACE satellite are provided by the Géodésie par Intégrations Numériques Simultanées (GINS) software developed by the Groupe de Recherche en Géodésie Spatiale (GRGS) in Toulouse, France, given realistic ephemeris and a EIGEN static gravity field model for imposing gravitational forces mainly due to the solid Earth acting on the twin satellites.

KBRR residuals are easily converted into variations of potential differences between the two satellites following the energy conservation method proposed earlier by $[13,14]$, so that along-track residual differences of potential mainly caused by continental hydrology variations can reach 0.1 $\mathrm{m}^{2} / \mathrm{s}^{2}$ with a precision of $10^{-3} \mathrm{~m}^{2} / \mathrm{s}^{2}$ [15].

\section{METHODOLOGY}

The Slepian function approach consists of two steps: (1) computation of the basis of regional orthogonal Slepian functions for the Niger watershed, and (2) the adjustment of the Slepian coefficients from the along-track GRACE KBRR data (see Section 3). More details on the SF methodology can be found in [16].

\subsection{Construction of a regional SF basis}

The main task to construct the Slepian Functions $\mathrm{F}$ for regions of arbitrary shape is to solve the eigenvalue equation by SVD analysis, as they are the eigenfunctions of an areabandwidth limiting operator $\mathrm{D}[3,16,17]$ :

$$
\mathrm{DF}=\lambda \mathrm{F}
$$

where $\mathrm{D}$ is the matrix formed by the distances between the points inside the geographical mask, e.g. the Niger basin.

For each eigenvalue $\lambda_{k}$ and its associated solution $F_{k}$ of (1), or Slepian functions, that maximizes the concentration of energy inside the region, so that eigenvalue is a measure of information density of the considered k-th SF.

Reconstruction of the hydrological signal $\mathrm{S}$ consists of summing the SF with weights (or coefficients) to be 
determined, e.g. from the satellite gravity data, up to a certain mode $\mathrm{K}$.

The approximate number of the pertinent SF to be kept is usually a quantity named Shannon number $K_{S}$. This threshold number characterizes roughly the stair-step nature of the $\lambda$ spectrum, it represents the number of useful functions that are necessary to expand a L-band limited signal within the region. Considering only the first eigenvalues of the highest energy, e.g. $\lambda>0.5$, drastically improves the signal-to-noise ratio with very small impact outside the region of interest $[3,18]$. In practice, Shannon number can be simply determined as the sum of all the eigenvalues normalized by their maximum value, e.g. $K_{S}=21$ for the Niger basin.

\subsection{Space reduction of the inverse gravity problem}

The damped Moore-Penrose solution of the problem to estimate the Slepian coefficient vector $\mathrm{C}$ is:

$$
\mathrm{C}=\left(\mathrm{B}^{* \mathrm{~T}} \mathrm{~B}^{*}\right)^{-1} \mathrm{~B}^{* \mathrm{~T}} \mathrm{Y}
$$

where $\mathrm{Y}$ is the $\mathrm{N}$-element vector containing the GRACE potential differences due to a surface distribution of sources (see Section 3), and $\mathrm{B}^{*}$ is the numerically-stabilized version of the pseudo-inverse operator given by:

$$
\mathrm{B}=\Gamma \mathrm{F}
$$

where the elements of the Newtonian potential matrix $\Gamma$ are given by [19] and $\mathrm{F}$ is the block-diagonal matrix of the SF (see Section 4.1). B* is constructed by keeping $99.9 \%$ of the energy of the total SVD spectrum of B for attenuation of illconditioning of the system. Note that using B of dimension $\left(\mathrm{N}, \mathrm{K}_{\mathrm{S}}\right)$ diminishes drastically the dimensions of the problem, as $\mathrm{K}_{\mathrm{S}}$ is generally of only several tens [16].

\section{RESULTS}

Figure 2 (up) shows the location of the main SF used to reconstruct the EWH time series over 6 years of GRACE data with a time step of 10 days. These main functions are located in the center of the Niger watershed, which indicates that, despite the complexity of the shape of the basin, the energy accumulated in these different modes is sufficient to reconstruct the climatic variability of the Niger watershed, as presented in Figure 2 (down).

The first modes $(K=1,2,3,4,6)$ exhibit the same seasonal fluctuations. They show a rainy season starting suddenly in May with maxima in June-July of $\sim 0.75$ (in 2003) to $\sim 0.4 \mathrm{~m}$ (in 2002) of EWH. Then a gradual decrease from September to March / April can be observed, with minima which show water deficits ranging from $-0.20 \mathrm{~m}$ (in 2002) to $-0.30 \mathrm{~m}$ (in 2003) of EWH.

Mode number 5 is more surprising because if it also shows seasonality, it is much weaker but also much smoother. It presents maxima in August / September ranging from $0.2 \mathrm{~m}$ (in 2007) to $0.1 \mathrm{~m}$ (in 2006) of EWH. It should be noted that there is therefore a shift of about 1 to 2 months with the other modes. This shift is also found during the dry season for minima, especially visible during the period 2005-2007. A closer look at the location of the SF of this 2-maxima mode (Figure 2 (up)) reveals that one peak is located in the western part where oceanic influence is important and the second peak is located at the limit of desert / semi-arid zones. Consequently, these very weak fluctuations shown in Figure 2 (down) can be explained by the oceanic influences which bring rains on the western part of the Niger watershed while the eastern part remains under the influence of the desert climate. Mode 5 therefore results from the integration of these two climatic influences and it shows that the western rainfalls are balanced by the water deficit of the desert area. These observations explain the weak variations observed in the time series and also the associated shift due to asynchronous oceanic arrivals.
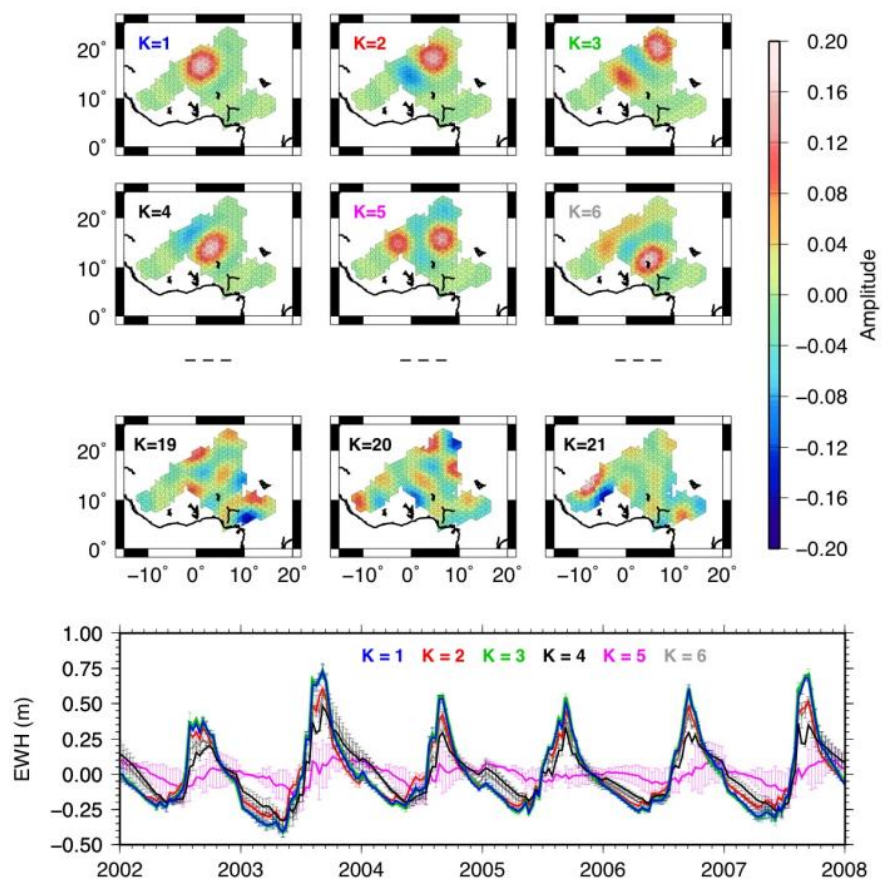

Figure 2. Spatial SF determined by SVD analysis for the Niger watershed up to the Shannon number 21 (up) and time series of these first SF modes adjusted every 10 days from the GRACE data (down).

\section{CONCLUSIONS}

We have here demonstrated the possibility for inverting GRACE KBRR to retrieve water mass density (expressed in EWH) without re-projection of SH coefficients on a SF basis, but applying an innovative approach based on regional $\mathrm{SF}$. 
We highlight that using a basis of only $\mathrm{K}=21 \mathrm{SF}$ coefficients is sufficient to restore the main hydroclimatic changes of the Niger watershed at the GRACE satellite resolution.

\section{REFERENCES}

[1] B. D. Tapley, S. Bettadpur, M. Watkins and C. Reigber, "The gravity recovery and climate experiment: mission overview and early results", Geophysical Research Letters, AGU, Volume 31, L09607, doi: 10.1029/2004GL019920, 2004.

[2] B. D. Tapley, M. M. Watkins, F. Flechtner, C. Reigber, S. Bettadpur, M. Rodell, I. Sasgen, J. S. Famiglietti, F. W. Landerer, D. P. Chambers, J. T. Reager, A. S. Gardner, H. Save, S. C. Swenson, C. Boening, C. Dahle, D. N. Wiese, H. Dobslaw, M. E. Tamisiea and I. Velicogna, "Contributions of GRACE to understanding climate change", Nature Climate Change, 9, 358369, doi: 10.10.38/s41558-019-0456-2, 2019.

[3] F. J. Simons and F. A. Dahlen, "Spherical Slepian functions and the polar gap in geodesy", Geophysical Journal International, 166(3), 1039-1061, doi: 10.1111/j.1365-246X.2006.03065.x, 2006.

[4] S.-C. Han and F. J. Simons, "Spatiospectral localization of global geopotential fields from the Gravity Recovery And Climate Experiment (GRACE) reveals the coseismic gravity change owing to the 2004 Sumatra-Andaman earthquake", Journal of Geophysical Research, 113, B01405, doi: 10.1029/2007JB004927, 2008.

[5] G. Cambiotti and R. Sabadini, "A source model for the great 2011 Tohoku earthquake $(\mathrm{Mw}=9.1)$ from inversion of GRACE gravity data", Earth and Planetary Science Letters, 335-336, 7279, doi:10.1016/j.epsl.2012.05.002, 2012.

[6] C. Harig and F. J. Simons, "Mapping Greenland's mass loss in space and time", Proc. Natl. Acad. Sci. U.S.A., 109, 19934-19937, doi: 10.1073/pnas.1206785109, 2012.

[7] A. K. Beveridge, C. Harig and F. J. Simons, "The changing mass of glaciers on the Tibetan Plateau, 2002-2016, using timevariable gravity from GRACE satellite mission", Journal of Geodetic Science, 8, 83-97, doi: 10.1515/jogs-2018-0010, 2018.

[8] X. Xie, C. Xu, Y. Wen and W. Li, "Monitoring groundwater storage changes in the Loess Plateau using GRACE satellite gravity data, hydrological models and Coal mining data", Remote Sensing, 10, 605, doi: 10.3390/rs10040605, 2018.

[9] M. von Hippel and C. Harig, "Long-term and inter-annual mass changes in the Iceland ice cap determined from GRACE gravity using Slepian functions", Frontiers in Earth Science, 7, 171, doi: 10.3389/feart.2019.00171, 2019.

[10] C. Harig, K. W. Lewis, A. Plattner and F. J. Simons, "A suite of software analyzes data on the sphere", Eos, 96, 18-22, doi: 10.1029/2015EO025851, 2015.

[11] J.-M. Lemoine, S. Bruinsma, S. Loyer, R. Biancale, J.-C. Marty, F. Pérosanz and G. Balmino, "Temporal gravity field models inferred from GRACE data", Advanced in Space Research, 39, 10, 1620-1629, doi: 10.1016/j.asc.2007.03.062, 2007.
[12] S. Bruinsma, J.-M. Lemoine, R. Biancale and N. Valès, "CNES/GRGS 10-day gravity field models (release 2) and their evaluation, Advances in Space Research, 45, 587-601, doi: 10.1016/j.asr.2009.10.012, 2010.

[13] C. Jekeli, "The determination of gravitational potential differences from satellite-to-satellite tracking", Celest. Mech. Dyn. Astro., 75, 85-101, 1999.

[14] S.-C. Han, C. K. Shum and C. Jekeli, "Precise estimation of in situ geopotential differences from GRACE low-low satellite-tosatellite tracking and accelerometer data", Journal of Geophysical Research, 111, B04411, doi: 10.1029/2005JB003719, 2006.

[15] G. Ramillien R. Biancale, S. Gratton, X. Vasseur and S. Bourgogne, "GRACE-derived surface mass anomalies by energy integral approach. Application to continental hydrology", Journal of Geodesy, 85, 6, 313-328, doi: 10.1007/s00190-010-0438-7, 2011.

[16] G. Ramillien, L. Seoane and J. Darrozes, "An innovative Slepian approach to invert GRACE KBRR for localized hydrological information at the sub-basin scale", Remote Sensing, SI: GRACE Satellite Gravimetry for Geosciences, 13(9), 1824, doi: 10.3390/rs13091824, 2021.

[17] A. P. Bates, Z. Khalid and R. A. Kennedy, "Efficient computation of Slepian functions for arbitrary regions on the sphere", IEEE Trans. Sig. Process., 65, 4379-4393, doi: 10.1109/TSP.2017.2712122, 2017.

[18] R. A. Kennedy and P. Sadeghi, Hilbert Space Methods in Signal Processing, Cambridge, Cambridge University Press, 2013.

[19] G. Ramillien, F. Frappart, S. Gratton and X. Vasseur, "Sequential estimation of surface water mass changes from daily satellite gravimetry data", Journal of Geodesy, 89, 3, 259-282, doi: 10.1007/s00190-014-0772-2, 2015. 